\title{
Cidade e memória: entre o desejo e o afeto
}

City and memory: between desire and affection

\author{
Adriana Mara Vaz de Oliveira* \\ Márcia Metran de Mello**
}

\begin{abstract}
Resumo
Este artigo propõe um mergulho na gênese da cidade de Goiânia, perquirindo a memória dos seus criadores e de seus moradores pioneiros. A euforia expressa no desejo e sonho de construir uma nova cidade manifesta-se claramente em todos os relatos oficiais que constituem a memória histórica de Goiânia. Aqueles que detinham o controle do desejo realizaram o sonho. A afeição de todos os pioneiros por aquele lugar inóspito foi garantida pelo desejo de consolidar a cidade nova e moderna, que se contrapunha ao antigo e atrasado representado pela cidade de Goiás. A memória compartilhada manifestou-se nos seus depoimentos.
\end{abstract}

Palavras-chave: Goiânia; Memória histórica; Memória dos pioneiros.

\begin{abstract}
This paper proposes a dip in the genesis of the city of Goiania, inquiring the memory of its creators and its pioneers residents. The euphoria expressed the desire and dream of building a new city, clearly manifests itself in all official reports which constitute the historical memory of Goiânia. Those who held the desire of control held dream. The affection of all pioneers in that inhospitable place was guaranteed by the desire to consolidate the new and modern city, which was opposed to the old and backward represented by the City of Goiás. The shared memory is expressed in their statements.
\end{abstract}

Keywords: Goiânia; Historical memory; Memory of the pioneers.

\section{Sobre o espaço e o tempo...}

Em 2003, o Instituto do Patrimônio Histórico e Artístico Nacional (IPHAN) aprovou o tombamento do acervo arquitetônico e urbanístico art déco de Goiânia, incluindo 22 edifícios e monumentos públicos e os traçados urbanos originais do centro de Goiânia e do núcleo pioneiro de Campinas. Daquele momento em diante, acelerou-se uma corrida em direção à celebração do passado da cidade, que as instâncias municipal e estadual não conseguiram sedimentar anteriormente.

\footnotetext{
* Doutora em História pela Universidade Estadual de Campinas (UNICAMP). Professora do Programa de Pós-graduação em Arquitetura e Urbanismo da Universidade Federal de Goiás (UFG).

** Doutora em Sociologia pela Universidade de Brasília (UnB). Professora do Programa de Pós-graduação em Arquitetura e Urbanismo da Universidade Federal de Goiás (UFG).
}

Recebido em abril de 2017 | Aprovado em setembro de 2017. 
Esse tombamento goianiense não destoa das preocupações contemporâneas em torno da preservação do passado ou emergência da memória, em contraste com o privilégio dado ao futuro no início do século passado, em que se troca o futuro presente pelo passado presente (HUYSSEN, 2000).

Entretanto, Goiânia já era uma metrópole. E, como tal, o seu centro e edifícios sofreram com a expansão urbana, conferindo-lhes novos usos e formas. Em busca de solucionar o hiato entre o tempo e o espaço, isto é, trazer o passado de volta ao centro da cidade, Goiânia foi objeto de uma série de ações, institucionalizadas ou não, que visavam recuperar a sua aura (BENJAMIN, 1983). Em princípios do século XX, esse autor discute a obra de arte em tempos de novas formas de reprodução técnica, discutindo a questão da autenticidade. A autenticidade para Benjamin (1983, p.8) "[...] é tudo aquilo que ela contém e é originalmente transmissível, desde sua duração material até seu poder de testemunho histórico [...]”, condições que ficaram abaladas diante do novo tempo e forma de produção artística, ou seja, fraqueja-se a aura. Desse modo, a recuperação da aura de Goiânia remete à capacidade do seu conjunto arquitetônico e urbanístico original retomar a força de testemunho histórico.

Ao longo do tempo, foram várias as ações concatenadas no intuito de recuperação da força simbólica do centro histórico. Alguns arquitetos propuseram um projeto que objetivava reaver as fachadas art déco em cores pastel e reformaram os canteiros da Avenida Goiás, cobrindo-os novamente de vegetação; a Secretaria de Cultura do Município criou o Centro de Referência e Memória no Grande Hotel - o primeiro edifício de Goiânia, até então abandonado - e encheu-o de música com o chorinho e o cinema na calçada; e grupos independentes articularam ações variadas em torno da ocupação da região central. De lá para cá, pouco mudou: o centro não recobrou a sua aura e poucos o reconhecem como lugar de memória. O que foi único e fruto de um investimento autêntico - a criação da cidade - perdeu-se com o tempo. Como isso aconteceu?

No dossiê de tombamento, percebeu-se a ausência de vínculos culturais e simbólicos do acervo preservado e, assim, foi apontada a importância da "memória arquitetônica" como articuladora da identidade da cidade. No documento, nota-se que há uma aposta no porvir e não na constatação verdadeira da ligação afetiva e identitária da população goianiense com seu lugar.

Perscrutando a relação entre memória e identidade, percebe-se que se tangenciam e podem até se fundamentar mutuamente, mas não são indivisíveis, ao 
ponto que uma só seja pensada perante a outra, conforme apontou o dossiê. Quando se fala em memória, pensa-se nos seus critérios constituidores - acontecimentos (pessoais e coletivos), personagens e lugares - como ensinou Pollak (1992). A citada memória arquitetônica seriam os lugares ou as pedras da cidade, como disse Halbwachs (1990). Esse quadro espacial interage com acontecimentos e pessoas resultando na memória, que é sempre seletiva e construída, social e individualmente. Por sua vez, a identidade, para Pollak (1992), é constituída por três elementos essenciais - a unidade física (pertencimento), a continuidade dentro do tempo (no sentido físico, moral e psicológico) e o sentimento de coerência (a percepção e a unificação do todo). A memória proporciona o sentimento de coerência e de continuidade de um grupo ou de uma pessoa em sua reconstrução de si (POLLAK, 1992, p. 204). A memória assegura a identidade, pois é um dos seus elementos constituintes. Logo, a memória goianiense deveria ter como referência espacial o acervo tombado, que, por sua vez, certificaria a sua identidade.

O propósito deste artigo não é discutir a questão patrimonial de Goiânia em si, mas perquirir a partir de um mergulho na gênese da cidade, em que a sua criação, como monumento intencional, é responsável pela fundação de uma memória. Para tal, percorre-se a memória dos seus criadores e de seus moradores pioneiros. A memória dos criadores de Goiânia é verificada nos depoimentos reunidos de forma oficial e a memória dos pioneiros é examinada nas declarações coletadas por um historiador. A intenção é mostrar como a tessitura de inventar uma cidade foi capaz de unificar discursos, criando um lastro identitário, que encontra pouca ressonância no acervo arquitetônico e urbanístico tombado há pouco mais de uma década.

\section{O desejo: a memória histórica}

O antropólogo francês Claude Lévi-Strauss (1957), em visita ao Brasil na década de 1930, registrou uma impiedosa e irônica impressão da nova capital de Goiás:

Visitei Goiânia em 1937. Uma planície sem fim, que parecia, ao mesmo tempo, um terreno baldio, um campo de batalha, eriçada de postes de eletricidade e de estacas de agrimensura, exibia uma centena de casas novas dispersas pelos quatro cantos do horizonte. A mais importante era o hotel, paralelepípedo de cimento, que, no meio desse achatamento, evocava uma aéro-estação ou um fortim; ter-se-lhe-ia aplicado de boa vontade a expressão "bastião da civilização", num sentido não mais figurado mas direto, que adquiria, com esse uso, um valor singularmente irônico. Pois nada poderia ser tão bárbaro, tão inumano, quanto esse empreendimento contra o deserto. Essa construção sem graça era o contrário de Goiás; nenhuma história, nenhuma 
duração, nenhum hábito havia saturado o seu vazio ou amenizado a sua rigidez; sentíamo-nos ali como numa estação ou num hospital, sempre passageiros e jamais residentes. Somente o temor dum cataclismo poderia justificar essa casamata. Produziu-se um, com efeito, cuja ameaça se prolongava no silêncio e na imobilidade reinantes. Cadmus, o civilizador, tinha semeado os dentes do dragão. Numa terra esfolada e queimada pelo hálito do monstro, esperava-se que nascessem homens. (LÉVI-STRAUSS, 1957, p. 128).

Essa visão apocalíptica, porém, não encontrava eco entre aqueles que inspiravam e administravam a mudança e construção da nova capital. O clima era de euforia desenvolvimentista e o desejo era de modernidade e progresso. Goiânia, uma publicação do IBGE em homenagem ao batismo cultural de Goiânia, ocorrido em 1942, é testemunha desse espírito. Traz a voz dos que formularam e operaram a mudança, dentre eles Getúlio Vargas, Pedro Ludovico Teixeira, Armando Augusto de Godói, Atílio Correia Lima, Venerando de Freitas e outros. O desejo era que essas vozes ecoassem no futuro, testemunhas da história:

Desta edição foram tirados em papel especial - Ruby - quinze exemplares que serão rubricados pelo Secretário-Geral do Conselho Nacional de Geografia, destinando-se um a figurar na urna em que será depositada a chave simbólica da cidade de Goiânia, a ser entregue à guarda da sua Prefeitura [...]. (IBGE, 1942, p. VIII).

Nas primeiras páginas da publicação estão as fotos, em grande dimensão, do interventor Pedro Ludovico Teixeira e do presidente Getúlio Vargas. A primeira com os dizeres: "Chefe do governo de Goiaz que, ao empreender e criar Goiânia no centro geográfico do País, para ser capital do seu estado, estabeleceu um ponto de apoio para o acesso das novas bandeiras civilizadoras aos sertões do planalto central." (IBGE, 1942, s. p.). A segunda com a mensagem: "Chefe do Govêrno dos Estados Unidos do Brasil, inspirador e orientador da nova Marcha para o Oeste e animador da construção de Goiânia.” (IBGE, 1942, s. p.). Estavam sublinhados os poderes estadual e federal, alinhados em um projeto nacional que pretendia beneficiar não só a região, mas todo o país. Nas citadas legendas dos dois políticos estava claro o caráter heroico de suas atuações. Seriam eles os dois primeiros homenageados da publicação como paraninfos do progresso.

O primeiro texto, trecho de um discurso feito em 1938, sob o título "O verdadeiro sentido de brasilidade é a Marcha para o Oeste", é de autoria de Vargas. Nele, o presidente falou em suprimir obstáculos e estender as fronteiras econômicas para a consolidação dos alicerces da Nação. Apresentou, para tanto, um plano de ações: 
Persistiremos na disposição de suprimir as barreiras que separam zonas e isolam regiões, de sorte que o corpo econômico nacional possa evoluir homogeneamente, e a expansão do mercado interno se faça sem entraves de nenhuma espécie. Reequipando portos, remodelando o material ferroviário, e construindo novas linhas, abrindo rodovias e aparelhando a frota mercante, conseguiremos articular, em função dêsse objetivo, os meios de transporte e os escoadouros da produção. Em conexão com tais empreendimentos, visando, precisamente, facilitar e garantir a sua execução, instalaremos a grande siderurgia, se necessário, por iniciativa do próprio Estado, ativaremos as pesquisas do petróleo e continuaremos a estimular a utilização, em maior escala, do carvão mineral e do álcool combustível. (VARGAS, 1942, p. 2).

No texto seguinte, "O problema da mudança da capital", trecho de um relatório que o interventor Pedro Ludovico Teixeira apresentou ao governo provisório em 1933, há clara referência à mudança da capital como solução para todos os problemas de Goiás, fazendo com que o desejo de Goiás seja o mesmo da Nação e reafirmando que a estratégia para a realização desse desejo está em uma articulação conjunta.

Pondo-nos em contacto permanente, diário e intensivo, com as necessidades de Goyaz, estudando-as nas suas fontes, perquirindo, observando, analisando detidamente as causas que teem impossibilitado o desenvolvimento econômico de um estado rico de reservas naturais como este, chegamos à convicção, já agora cimentada por mais de 30 meses de governo e investigações, de que a mudança da capital não é apenas um problema da vida de Goiaz. É também a chave, o começo de solução de todos os demais problemas. Mudando a sede do governo para um local que reúna os requisitos de cuja ausência absoluta se ressente a cidade de Goiaz, teremos andado meio caminho na direção da grandeza desta maravilhosa unidade central. (TEIXEIRA, 1942, p. 5)

Digno de nota é o "Relatório sobre a conveniência da mudança da capital", apresentado a Pedro Ludovico, em 1933, por Armando Augusto de Godói, engenheiro da Prefeitura do Rio de Janeiro. Nesse relatório, Armando apresentou o resultado de sua inspeção dos arredores de Campinas, local pretendido para a construção da nova capital. Introdutoriamente, o engenheiro dissertou sobre a cidade moderna e sua ação civilizadora e econômica.

Outrora, as cidades eram quase lugar somente de recreio e de exibição de riqueza, onde só se desenvolviam atividades sem fins econômicos, tendo como função preponderante a de teatro para o gôzo desenfreado das fortunas provenientes do trabalho agrícola. As agremiações urbanas tinham, sob o ponto de vista material, antes um destino parasitário, consumindo muito mais que produziam. Hoje, graças à evolução social e à circunstância de ter a humanidade entrado francamente na fase industrial, a cidade moderna é um centro de trabalho, uma grande escola em que se podem educar, desenvolver e apurar os principais elementos do espírito e do físico do homem e uma fonte de poderosas energias sem as quais os povos não progridem e não prosperam. É das cidades modernas que partem os vigorosos impulsos coletivos e é nelas que se faz a coordenação os movimentos e das atividades de uma nação. (GODÓI, 1942, p. 14). 
Godói se preocupou com as grandes despesas inerentes à construção de edifícios públicos. Para ele havia um preconceito que ligava a beleza desses edifícios ao luxo, acarretando despesas astronômicas em sua construção. Por essa observação pode-se supor que ele talvez soubesse que o apoio do Governo Federal à materialização de Goiânia fosse mais político que financeiro e que, portanto, haveria pouca verba para as obras. Assim, um "[...] edifício público não precisa ser constituído por materiais caros para se impor à admiração geral, sob o ponto de vista estético. A beleza de uma construção está na relação das suas diferentes partes e na distribuição de seus volumes." (GODÓI, 1942, p. 17).

Em 1935, o arquiteto urbanista Atílio Correia Lima apresentou ao interventor Pedro Ludovico Teixeira o "Plano Diretor da Cidade", documento publicado na coletânea do IBGE. Nele, Lima admitiu que criou um centro administrativo com grande carga simbólica.

\footnotetext{
Da topografia tiramos partido também para obter efeitos de perspectiva, como o motivo principal da cidade, que é o centro administrativo. Domina este a região e é visto de todos os pontos da cidade e principalmente por quem nela chega. As três avenidas mais importantes convergem para o centro administrativo, acentuando assim a importância deste em relação à cidade, que na realidade deveu-lhe a sua existência. (LIMA, 1942, p. 48).
}

Embora de forma relativizada, buscando ajuste de escala, Lima (1942, p. 48) declarou a inspiração barroca no desenho do plano da cidade. É certo que a teatralidade barroca haveria de evidenciar a função da nova cidade como centro de poder: "Guardando as devidas proporções, o efeito monumental procurado é o do princípio clássico adotado em 'Versailles', 'Carlsruhe' e 'Washington'”.

Goiânia é um texto da coletânea do IBGE advindo de uma palestra proferida pelo prefeito da capital, Venerando de Freitas, na Sociedade "Amigos de Alberto Tôrres" no Rio de Janeiro. Não há indicação de data, mas presume-se, pelo seu conteúdo, que seja dos primeiros anos de vida nova capital. Refere Venerando de Freitas (1942):

Goiânia significa muito no terreno do progresso material. Mais que isso, porém, representa e consubstancia a realização de um objetivo e a concretização de um ideal de gerações e de um imperativo geográfico, político, social e econômico. Transformando o ambiente, impôs uma mentalidade nova, sadia e idealista, trabalhadora e arrojada, capaz de destruir preconceitos e traçar diretrizes fecundas ao futuro de Goiaz. (FREITAS, 1942, p. 58). 
Segundo o prefeito, as melhorias estenderam-se a vários âmbitos, como na higienização dos gêneros alimentícios, pois, ainda em 1935, não se valorizava esse aspecto da vida urbana.

Contando que se pagasse a taxa estipulada, qualquer pessoa, em qualquer prédio ou recipiente, poderia explorar o produto de sua fabricação ou carne verde ou sêca, sem a censura médica do animal a ser abatido. Hoje, sobre isto, apenas bastam a obra imponente do mercado, as instalações sanitárias dos açougues, a fiscalização e o interêsse dos Poderes Municipais, fixando tabelas de preços a varejo, horários e lugares para exploração do comércio de alimentos como: carne, ovos, hortaliças, etc. que veem das fazendas. (FREITAS, 1942, p. 64).

O prefeito, nesse texto, considerou a cidade como concretização dos anseios dos que idealizaram a mudança, trazendo frutos já nos seus primeiros e verdes anos.

\begin{abstract}
Sôbre o que Goiânia tem trazido para o Estado, seria necessário um compêndio estatístico para demonstrar a sua colaboração como fonte de rendimento, turismo e mesmo nivelamento intelectual, colocando Goiaz na vanguarda dos Estados pioneiros do Novo Regime. As cidades, como os homens, teem a sua vida psíquica: Goiânia, intelectualmente estudada, não se pode comparar a nenhuma outra cidade do Estado. (FREITAS, 1942, p. 65).
\end{abstract}

Assim, o livro editado pelo IBGE em 1942 traz o registro do desejo de realização de um plano político, social, econômico e urbanístico, o pensamento de seus mentores e o testemunho de sua materialização em seus primeiros anos. A ideia de desejo realizado teima em contestar Claude Lévi-Strauss: numa terra esfolada e queimada pelo hálito do monstro, nasceram muitos homens.

\title{
O afeto: a memória dos pioneiros
}

O livro Memórias goianienses de José Mendonça Teles foi escrito e publicado em 1986 e concerne a uma coletânea de depoimentos de vinte e seis pioneiros de Goiânia, chamado de livro-testemunho pelo autor. Reeditado em 2012, o texto indica o cumprimento de seu papel, já que nessa data quase todos os depoentes haviam falecido. Tratou-se claramente de um arranjo que contemplava pessoas ligadas ao interventor do Estado - "[...] aqueles que chegaram primeiro e ajudaram Pedro Ludovico na tarefa heroica de levantar esta cidade" (TELES, 2012, p. 7) -, não arregimentando ninguém contrário à ideia da nova capital. Contudo, tal característica do rol de entrevistados não invalida a iniciativa, pelo contrário, enriquece-a, pois permite perceber, por meio dos 
depoimentos, como a construção de uma imagem de cidade se consolidou, ainda que as circunstâncias cotidianas não correspondessem ao sonho.

José Mendonça Teles (2012) apresenta seus entrevistados:

[...] Resta, ainda, (e até quando?) a fala dos pioneiros, e ela surge, emotiva e franca, nas páginas deste livro. É a história de Goiânia, contada desde quando a ideia mudancista já acalentava o sonho de Pedro Ludovico até o Batismo Cultural, em 1942, data que fixei como encerramento do primeiro ciclo de pioneiros. E eles estão aqui: Acary de Passos Oliveira, Antônio Henrique Peclat, Bernardo Élis, Célia Coutinho Seixo de Britto, Colemar Natal e Silva, Dante Ungarelli, Eduardo Bilemjian, Eleonora Loyola Azeredo, Gerson de Castro Costa, Josaphat Nascimento, José Júlio de Guimarães Lima, Leyde Jayme, Manoel Bento Costa, Mariana Augusta Fleury Curado, Marilda Godói de Carvalho, Nelly Alves de Almeida, Ofélia Sócrates do Nascimento Monteiro, Oscar Sabino Júnior, Paulo Augusto de Figueiredo, Paulo Fleury da Silva e Sousa, Paulo Gomide Leite, Pedro Osório, Rosarita Fleury, Venerando de Freitas Borges, Waldemar Gomes de Melo e Waldomiro Bariani Ortêncio. (TELES, 2012, p. 8).

Os pioneiros eram, preponderantemente, funcionários públicos do Estado anteriores à mudança ou não -, filhos ou filhas de pessoas ligadas ao poder público, professores e profissionais liberais. A maioria nascida em Goiás, muitos desses na antiga capital, e os demais vindos de outros estados ou mesmo do exterior. Os relatos masculinos foram em maior número. Esses dados ajudam a pensar sobre o lugar daqueles que tecem os depoimentos.

As memórias dos pioneiros concentram-se em duas questões: o apoio à nova capital e as peculiaridades cotidianas. Em relação à primeira questão, todos são unânimes em afirmar a liderança de Pedro Ludovico no tocante à mudança e construção de Goiânia, como Costa e Ungarelli, respectivamente, expressam nas suas falas:

Sua grande paixão político-administrativa foi a mudança da capital, a construção de Goiânia. Para isso, sacava dos fundos seculares do passado a chama do ideal de outros governantes e a vitalizava com o ardor de jovem enamorado, sonhando e realizando. Por essa fixação, enfrentou dissabores e atropelos, vencendo-os, e provando que somente um espírito de grande espectro telepático do futuro é capaz de grandes obras. [...]. (TELES, 2012, p. 112).

[...] Eu quero dizer que Goiânia é uma epopeia, Goiânia é um marco profundo na história da humanidade, não é de Goiás apenas. Nasceu de uma vontade férrea de um homem extraordinário, um homem que deixou exemplo de trabalho e coragem. [...]. (TELES, 2012, p. 78).

Contudo, havia aqueles que desconfiavam do sucesso daquela empreitada, como afirmou Acary Passos (TELES, 2012, p. 14): “[...] eu não acreditava que Goiânia fosse chegar ao que está. Tanto é verdade, que quando Dr. Pedro me deu a planta da cidade 
para vender lotes, eu disse a ele que ia fazer isso, mas consciente do meu fracasso". Mesmo diante da desconfiança, o sentimento que se reconhece entre os pioneiros é de credulidade na cidade capitaneada por Pedro Ludovico.

No que concerne às circunstâncias encontradas na nova cidade, há unanimidade na descrição da precariedade das condições, mas adoçadas pelo convívio fraterno entre aqueles que se aventuravam a construir Goiânia. Em 1936, o fotógrafo Eduardo Bilemjiam (TELES, 2012, p. 88) descreveu o que viu:

\begin{abstract}
Quando fui conhecer Goiânia, era tudo vazio. A cidade era longe, não havia condução. Não me lembro como fui lá, com algum caminhão ou bicicleta. $\mathrm{O}$ Grande Hotel estava em acabamento. O Palácio do governo estava no alicerce. $\mathrm{Na}$ rua 20 , algumas casas em acabamento, outras prontas. $\mathrm{Na}$ margem do Botafogo, no rumo da Av. Anhanguera, havia algumas casas de madeira [...]. Goiânia era isso, não havia mais nada. (TELES, 2012, p. 88).
\end{abstract}

Outra pioneira, Maria Augusta Curado, relatou, para o mesmo período, a ausência de água encanada, a presença de uma precária feira livre e dos redemoinhos de poeira nos dias de sol quente, energia elétrica deficiente (TELES, 2012, p. 150-151). Sobre isso, Oscar Sabino disse: "a cidade era mal-iluminada, sendo frequentes as interrupções do precário e primitivo sistema elétrico. Acontecia, muitas vezes, de a cidade ficar na escuridão" (TELES, 2012, p. 195). Sobre os momentos de descanso, o primeiro prefeito da cidade Venerando de Freitas Borges relatou:

Goiânia era totalmente desprovida de centros de diversão. Não havia clube nem salões de festas. As nossas reuniões festivas, antes da inauguração do Grande Hotel, aos sábados, eram feitas ao abrigo da velha amoreira, que ainda existe na rua 24. Sob suas frondes foi armado um tablado. (TELES, 2012, p. 250).

Em todos, há a menção à poeira, um problema recorrente e frequente, como falou Gerson Costa:

[...] pode-se dizer que a cor predominante era marrom. A cor do pó, poeira. Esta impregnava os cabelos, as sobrancelhas, os narizes, as mãos, os colarinhos, as camisas e blusas, os vestidos e saias, os sapatos. Era o festival cromático do progresso. (TELES, 2012, p.108).

No mesmo ano, ainda que a cidade não estivesse acabada, ou melhor, estava iniciada, tanto em termos urbanísticos quanto arquitetônicos, o professor Antônio Peclat disse: "Goiânia de meu tempo era uma felicidade. Eu saía de minha casa para lecionar 
no Liceu, indo catando gabiroba pelo caminho" (TELES, 2012, p. 20). Para Bernardo

Élis a impressão não era diferente, ainda que com um olhar mais consciente:

No começo, Goiânia era formidável. Não havia, como nas demais cidades, pessoas ou famílias privilegiadas. [...] Podia-se fazer o que quisesse, e o campo era livre para quem fosse mais audaz ou possuidor de criatividade. Para coroar, havia enorme entusiasmo, o imenso orgulho das pessoas que aqui trabalhavam e viviam, para quem Goiânia já era uma empresa vitoriosa e uma cidade plenamente realizada. Mas isso não era verdade, e Goiânia era, simplesmente, um enorme acampamento sem água, sem luz e sem esgoto, onde um quarto para morar era difícil de encontrar e, quando encontrava, era caro, onde as pensões e casas de pastos eram raras, onde não havia nem leite nem frutas. [...] Apesar das dificuldades, as casas tinham privada patente dentro de casa e banheiro de chuveiro, além de ser portadora de uma nova mentalidade mais aberta e progressista. De qualquer maneira, a vida em Goiânia era melhor e oferecia perspectiva de progresso que em Goiás não existia. (TELES, 2012, p. 26).

A pioneira Célia Coutinho reafirma as difíceis circunstâncias do início da cidade - "sem reclamações, com espírito de sacrifício e colaboração, todos se alojavam como podiam, não havia outro jeito". E continua:

[...] como diversas pessoas e mesmo famílias inteiras, também fazíamos refeições na histórica e agradável pensão de D. Maruca, próxima ao Botafogo, numa das casas do gracioso conjunto de madeira lá improvisado no começo da construção da cidade. (TELES, 2012, p. 43).

Observa-se que a conformação conduz o depoimento, como comprova o adjetivo "gracioso" ao precário barraco de madeira.

A visão do sacrifício em prol de um bem comum é encontrada também no relato de Gerson Costa:

Os primeiros dias desta bela cidade foram de uma família provinciana que vivia solidária consigo mesma: seus irmãos eram irmãos. [...] Aqui, ou havia demais, ou não havia nada. Havia demais: poeira, falta de produtos alimentícios, ausência de médicos, de habitações suficientes, de luz elétrica, de meios de transportes, mesmo urbanos, muito trabalho e, sobretudo, muitos sonhos. Não havia nada: luxos, malquerenças, brigas, rivalidades, roubos, sequestros etc. (TELES, 2012, p.106).

O sentimento de dever cumprido também é encontrado nos depoimentos, como no de Dante Ungarelli, ao dizer:

[...] mas estamos satisfeitos, porque fizemos uma cidade, ajudamos a construir uma cidade, que eu considero, um refúgio pecatorum, porque até os criminosos de outras plagas que para aqui vêm, corrigem-se e prosperam. Uma cidade bendita. (TELES, 2012, p. 78). 
As narrações dos pioneiros se repetem e se completam. Todos cumprem o papel de enaltecer Pedro Ludovico, assim como de apontar os problemas na cidade recémcriada em contraposição ao espírito desbravador que os unia, dotando-os de fraternidade no convívio cotidiano. As descrições só são alteradas quando refletem sobre Goiânia na década de 1980, o tempo em que falavam. Bernardo Élis expressou o rompimento com o sonho do início com significativa acidez:

\footnotetext{
Será que se concretizou sonho tão generoso? Acho que não. Goiânia não passou de um grande mercado imobiliário que enriqueceu meia dúzia de famílias, enquanto seus arredores se enchiam de favelas. [...]. (TELES, 2012, p. 31).
}

\section{Considerações finais}

A seleção dos depoimentos oficiais e dos pioneiros se inspirou na montagem de Walter Benjamin, por ser o

[...] método deste trabalho: montagem literária. Não tenho nada a dizer. Somente a mostrar. Não surrupiarei coisas valiosas, nem me apropriarei de formulações espirituosas. Porém, os farrapos, os resíduos: não quero inventariá-los, e sim fazer-lhes justiça da única maneira possível: utilizandoos. (BENJAMIN, 2006, p. 502).

Essa metodologia inspira-se diretamente nas práticas urbanas do autor que a propõe como mecanismo de fazer um caleidoscópio da cidade e de suas experiências. Imagens, recortes de revistas, anotações, fragmentos, enfim, tudo era objeto passível de "montar" uma desordem, para formular questões, abrir caminhos, apontar reflexões. A finalidade desse artigo coaduna-se com essa metodologia.

A euforia expressa no desejo e sonho de construir uma nova cidade manifesta-se claramente em todos os relatos oficiais que constituem a memória histórica de Goiânia. Aqueles que detinham o controle do desejo realizaram o sonho. A afeição de todos por aquele lugar inóspito foi garantida pelo desejo de consolidar a cidade nova e moderna, que se contrapunha ao antigo e atrasado representado pela cidade de Goiás. A memória cultivada e compartilhada ali se reproduziu nos depoimentos dos pioneiros.

No entanto, se voltarmos ao tombamento do centro histórico e de seus edifícios percebe-se que não há o mesmo retorno, ou seja, os goianienses não cultivaram uma memória compartilhada, porque lhes faltou uma imagem de cidade a ser da mesma 
forma desejada e reverberada. Os sonhos e desejos de Pedro Ludovico redundaram numa memória social em que todos se viam imbuídos de construir aquela cidade.

Atualmente, não há reverberação e os moradores de Goiânia não estabelecem conexões de pertencimento com o acervo tombado e pouco com a cidade como um todo. O programa de educação patrimonial fundado junto à rede municipal de ensino, no bojo do tombamento, foi extinto. A maioria da população desconhece qualquer referência ao acervo tombado. Todos os dias têm-se notícias sobre a demolição de edifícios significativos na região central e há pouca mobilização no sentido de impedimento ou de desagravo. O descaso do poder público com o centro histórico é evidente, apesar da sua densa e fervilhante ocupação. Enfim, há sinais irrefutáveis que o monumento intencional chamado Goiânia, baluarte da modernidade goiana, expresso atualmente no seu centro histórico, não foi capaz de perpetuar laços de afetividade com sua população.

Para Pollak (1992), criadores e pioneiros compartilhavam um sentido de coerência identitário no momento de fundação de Goiânia e o exprimiram em suas memórias. O tempo e o crescimento da cidade dissiparam essa força inicial e nada foi articulado no sentido de sua permanência. A memória tem de ser trabalhada cotidianamente, porque, senão, continuaremos a nos deparar com depoimentos como o de Bernardo Élis, que disse: "um pioneiro como eu pode dizer hoje que não foi essa a Goiânia sonhada ontem" (TELES, 2012, p. 31). 


\section{REFERÊNCIAS}

BENJAMIN, Walter et al. Textos escolhidos. Tradução: José Lino Grünnwald et al. São Paulo: Abril Cultural, 1983.

BENJAMIN, Walter et al. Passagens. Belo Horizonte: Ed. UFMG, 2006.

FREITAS, Venerando de. Goiânia. In: IBGE. Goiânia: coletânea especialmente editada pelo Instituto Brasileiro de Geografia e Estatística como contribuição ao Batismo Cultural de Goiânia. Rio de Janeiro: IBGE, 1942.

GODÓI, Armando Augusto. Relatório sobre a conveniência da mudança da capital. In: IBGE. Goiânia: coletânea especialmente editada pelo Instituto Brasileiro de Geografia e Estatística como contribuição ao Batismo Cultural de Goiânia. Rio de Janeiro: IBGE, 1942.

HALBWACHS, Maurice. A memória coletiva. Tradução: Laurent Leon Shaffter. São Paulo: Vértice; Ed. Revista dos Tribunais, 1990.

HUYSSEN, Andreas. Seduzidos pela memória. Tradução: Sérgio Alcides. Rio de Janeiro: Aeroplano, 2000.

IBGE. Goiânia: coletânea especialmente editada pelo Instituto Brasileiro de Geografia e Estatística como contribuição ao Batismo Cultural de Goiânia. Rio de Janeiro: IBGE, 1942.

LÉVI-STRAUSS, Claude. Tristes trópicos. São Paulo: Anhembi, 1957.

LIMA, Atílio Correia Lima. Plano Diretor da Cidade. In: IBGE. Goiânia: coletânea especialmente editada pelo Instituto Brasileiro de Geografia e Estatística como contribuição ao Batismo Cultural de Goiânia. Rio de Janeiro: IBGE, 1942.

MANSO, Celina Fernandes Almeida (Org.). Goiânia art déco: acervo arquitetônico e urbanístico: dossiê de tombamento. Goiânia: SEPLAN, 2004. 3 v.

POLLAK, Michel. Memória e identidade social. Revista Estudos Históricos, Rio de Janeiro, v. 5, n.10, p. 200-212, 1992.

TEIXEIRA, Pedro Ludovico. O problema da mudança da capital. In: IBGE. Goiânia: coletânea especialmente editada pelo Instituto Brasileiro de Geografia e Estatística como contribuição ao Batismo Cultural de Goiânia. Rio de Janeiro: IBGE, 1942.

TELES, José Mendonça. Memórias goianienses. 2. ed. Goiânia: Ed. PUC-GO, 2012.

VARGAS Getúlio. O verdadeiro sentido de brasilidade é a Marcha para o Oeste. In: IBGE. Goiânia: coletânea especialmente editada pelo Instituto Brasileiro de Geografia e Estatística como contribuição ao Batismo Cultural de Goiânia. Rio de Janeiro: IBGE, 1942. 